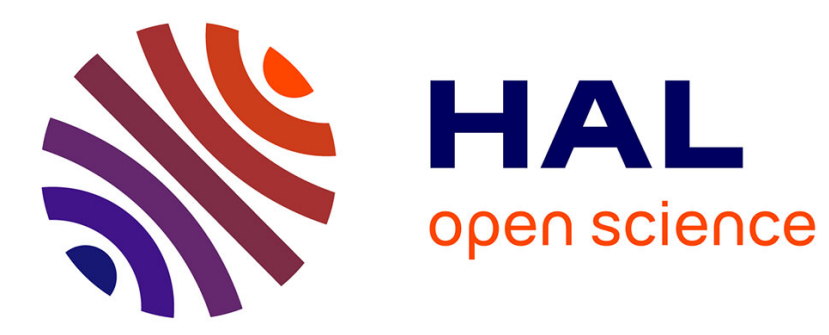

\title{
Can simplicity help?
}

Jean-Yves Blaise, Iwona Dudek

\section{To cite this version:}

Jean-Yves Blaise, Iwona Dudek. Can simplicity help?. ACM International Conference Proceedings Series, 2014, i-KNOW 2014 - Knowledge Visualization, paper 17 (8p). 10.1145/2637748.2638414. halshs-01074206

\section{HAL Id: halshs-01074206 https://shs.hal.science/halshs-01074206}

Submitted on 13 Oct 2014

HAL is a multi-disciplinary open access archive for the deposit and dissemination of scientific research documents, whether they are published or not. The documents may come from teaching and research institutions in France or abroad, or from public or private research centers.
L'archive ouverte pluridisciplinaire HAL, est destinée au dépôt et à la diffusion de documents scientifiques de niveau recherche, publiés ou non, émanant des établissements d'enseignement et de recherche français ou étrangers, des laboratoires publics ou privés. 


\section{Can simplicity help? \\ Jean-Yves Blaise \\ CNRS (UMR 3495 MAP) \\ 31 chemin Joseph Aiguier \\ 13288 Marseille Cedex $20(\mathrm{~F})$ $+33491164342$ \\ jean-yves.blaise@map.archi.fr

\author{
Iwona Dudek \\ CNRS (UMR 3495 MAP) \\ 31 chemin Joseph Aiguier \\ 13288 Marseille Cedex $20(\mathrm{~F})$ \\ +33491164342 \\ iwona.dudek@map.archi.fr
}

\begin{abstract}
Analysts are today given (or develop) a wide range of powerful visual reasoning tools, of leading-edge platforms where services like high interactivity, high computing capacity, structured knowledge, processing of complex reasoning tasks on massive data, are duly implemented. Classic XVIIIth or XIXth century dataviz solutions may then appear as respectable, but deprecated far too simple to match today's challenges. In this paper we try to show that the very simplicity of these solutions can still be of help in problem-solving situations. We first revisit some great classics in order to uncover patterns and exceptions inside a data set consisting of incomplete historical evidence on groups of stalls that used to be located on the market square in Cracow. We show that, once reinterpreted and re-implemented, classic visualisations like Charles De Fourcroy's tableau poléométrique or Munehisa Homma's candlestick chart do help the analyst to re-read the data, and to augment his level of knowledge. We then introduce an online, free to use implementation of these classics that we expect to weigh through a sort-of crowdsourcing approach to which extent they can act as relevant and generic visual formalisms. Finally, we underline the potential contribution of this research in terms of methodology, and discuss in what simplicity proves here helpful.
\end{abstract}

\section{Categories and Subject Descriptors \\ H.3.3, H.5.2, J.5, H.1, H.2.5, H.2.8, H.3.1}

\section{General Terms}

Documentation, Design, Experimentation, Human Factors,

\section{Keywords}

Historical sciences, Methodology, Spatio-temporal data, Information visualization, Visual formalisms.

\section{CONTEXT \& MOTIVATION}

With the introduction of computer platforms, a wide range of new solutions have little by little emerged and now allow analysts to manipulate, structure, and re-read temporal or spatio-temporal data sets. A number of leading-edges approaches and examples can for instance be found in state-of-the-art compilations like [1], [2], [3], [4], etc. And indeed the introduction of computer-based visualisations has clearly dramatically changed the way we design and produce graphics, the way we use vision to think, to say it with B.Scheidermann's words [5].

High levels of interactions, as well as updatability, are obviously key factors in this shift from "hand-drawn" graphics to nowadays complex information visualisation and visual analytics platforms. But other computer-dependent services could also be quoted like the handling of massive and/or real-time data sets, data preprocessing, user configurations, etc. Accordingly, visual reasoning solutions have been introduced in a wide range of activities and processes, from for instance exploratory analysis of spatiotemporal data [6] to massive text data analyses [7], or from the real-time detection of events [8] to the handling of uncertain data [9]. Animated graphics, although not necessarily suitable in many analytical processes can also be used as complement, or to trigger attention - a convincing evaluation of the respective pluses and minuses of static and animated graphics can be found in [10].

In short, as a result of this evolution, not only the making but the use of visualisations has known a very deep change. Yet, some most respected authors in the data visualisation community have put a strong focus on old, hand-drawn, pre-computer era visual solutions. The first name that will come to the mind of the reader will probably be this of E.R Tufte [11][12][13][14]: his influence is indeed a major one. But we definitely can also mention here the works of M.Friendly [15] or G.Palsky [16], and on temporal data the Cartographies of Time by D.Rosenberg and A.Grafton [17].

Naturally a number of past-time innovations these authors quote are today used on an everyday basis: typically Playfair's pie charts or bar charts, or Von Mayr's star plot for instance.

By contrast, some of these innovations seem still unrivalled: Minard's Russian campaign, described by [11] [14] as "the best graphics ever", has been commented and challenged many times [19][20]. Blanchet's 1840 catholic ladder [17] introduces a multiple-granularity representation of time that still acts as food for thinking for designers.

Finally, some concepts seem to be more or less forgotten, or are used in narrow disciplines, although they actually are generic solutions - Marey's train schedule could be quoted here [11].

Yet our motivation is not to comment on hand-drawn visual formalisms, or to eulogize great Masters. Our intent is to show, in a specific problem-solving situation, how a reinterpretation of "old" formalisms helped us to re-investigate a data set.

Simplicity the way we shall discuss it should therefore not be interpreted as specific to hand-drawn graphics: it should be 
understood in the sense of Maeda's laws of simplicity [21]: “ $a$ way to recognize design itself" [22].

In the next section we briefly present previous works, so as to position this contribution inside its context. We then detail the data set and the issues behind it. Following, we present our reinterpretation and implementation, and the findings they helped us reach. Finally, the evaluation section introduces a generic, online, free to use implementation of these classics. The conclusion section will focus on how revisiting classics can be considered in terms of workflow, how it can act as food for rethinking a data set, and ultimately in what exactly we think simplicity does help.

\section{BACKGROUND AND PREVIOUS WORK}

We have over the years implemented a rather exhaustive information system on the evolution of the Market Square in Cracow (40 built structures, over a hundred documented changes, time span of approximately a millennium) and proposed a series of visualisations dedicated to various reasoning tasks [23][24][25][26]. Typically, we have tried to describe and compare lifelines, spatial layouts, amount and quality of historical evidence, types of changes over time, correlations between the construction activity and external factors, etc.

This fine-grain analysis proved here and there to be difficult, due to the very nature of historical evidence (incomplete, unevenly distributed in time, imprecise, untrustworthy, etc.), but it did lead to a series of global (visual) pictures of what is actually known about that site. The system is developed on a robust but rather elementary implementation, combining RDBMS and/or XML data sheets, Perl scripts, SVG / XML/ HTML outputs produced on the fly. The inputs and results presented in this paper are handled inside this technological context.

Coming back to Cracow's Market Square, it hosted, like most such urban spaces inside European medieval towns, a variety of buildings and functions, ranging from administrative structures to commercial facilities. Here specifically, as a result of the Market Square's dimensions $(200 \mathrm{~m} * 200 \mathrm{~m}$, one of the largest in Europe), quite a lot of functions co-existed: the town hall compound alone comprised housing for the town authorities, a granary, a prison, a tavern, a garrison. The Market Square comprised in addition two municipal scales, a church, and a large number of commercial facilities.

Furthermore, the size and type of construction strongly varied, from the huge brick-built Cloth hall (over 100 meters long) to small more or less temporary wooden structures when talking about commercial facilities alone. Naturally, not only do the edifices differ in terms of size, construction, function, but our level of knowledge about each of them strongly differs.

Among the 40 built structures we have analysed over the years, several small-scale wooden commercial facilities (Figure 1) share rather challenging particularities:

- They cannot be precisely localised within the market square (known only in archival sources by expressions such as "close to the town hall" or "located in the northern sector"). Moreover, they were wooden structures, and were demolished during the XIXth century. There is accordingly no archaeological indication we can count on.

Almost no direct visual or textual archival material can be found that would help analysts say what were their construction and spatial layout. In fact, these facilities may even not have been "buildings" in the proper sense: they could have been rows of movable stalls, not physically connected to one another, but considered as a consistent group basing on their common function (goods/services sold).

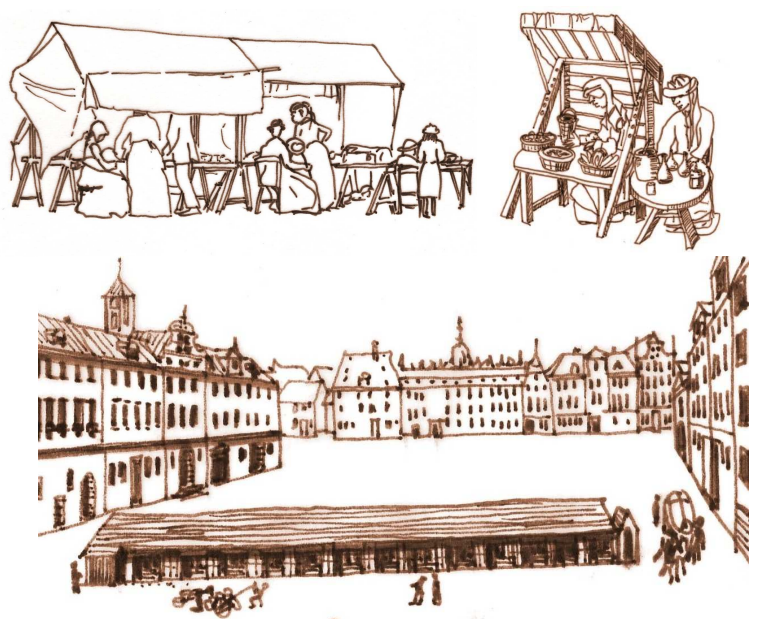

Figure 1: Some of the many possible layouts and shapes of wooden stalls.

We shall focus here on eight such structures, namely: "Lithuanian stalls", "stalls near the town hall", "Hatters' stalls", "Glass stalls", "Food stalls", "stalls near the minor traders' hall", "butter stalls" and "gingerbread stalls" (Figure 2).

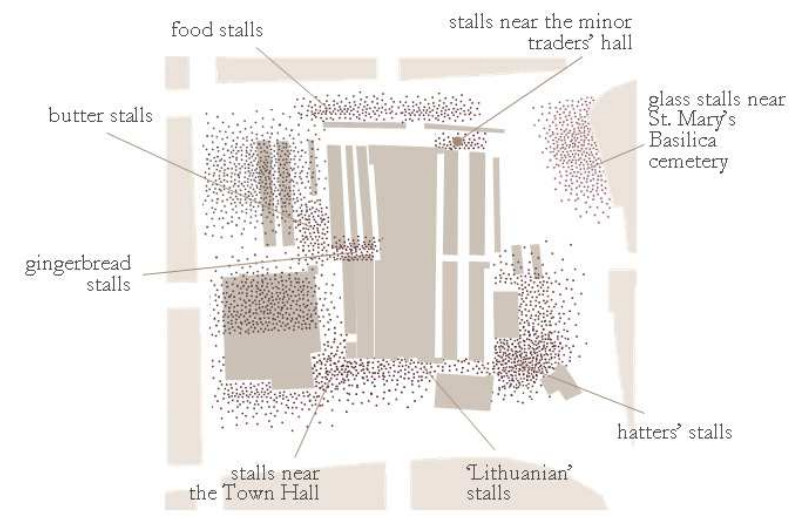

Figure 2: Approximate position of our groups of wooden stalls in Cracow's Market Square.

If very little is known about these commercial facilities (in fact temporal aspects are better known than spatial aspects, which is not that common), we do have one document that gives useful indications: an 1760 inventory conducted by Cracow's municipal authorities of the time. The inventory does not give indications on where the facilities were, how they looked like, but provides the following information:

name of the structure,

- a "sequence number" for each stall inside the facility (however the inventory does not mention what this number actually means - it can be interpreted as the chronological order of the inventory, as well as the spatial order from the beginning to the end of a row for example).

- name of owner 
- width and depth of each stall inside a structure (given in a local unit, ells, with a granularity of a quarter of ell)

- tax (amount) before 1760, called "census antiquus"

- tax (amount) after 1760, called "census novus"

Some other indications are given, but not for each stall (typically, what product is sold). Finally there are some specific stalls for which crucial data is missing (size or tax amounts) - a rather expectable pattern in historical data sets.

It has to be said at this stage that reasoning in one go both on complete and incomplete data (and without asking the analyst to "fill in the missing data") is crucial in Historical Sciences. Our research question can now be laid down openly: could these scarce pieces of information help us gain some understanding of the architecture, of the use and of the urban layout of these facilities (spatial layout, consistency of stalls inside a facility, economical background and rules for a given structure)? More precisely, two main questions emerge:

- can something be said about patterns of distribution in space ?

- can something be said about the tax policy in general, and the tax increase in 1760 ?

With such a limited amount of data, and rather basic research questions, we have considered it was worth trying to start by revisiting some great classics - Charles De Fourcroy's tableaux poléométriques and Munehisa Homma's candlestick charts. In a later experiment we also tested C.J Minard's tableaux graphiques - this we mention in the conclusion section.

These visual formalisms turned out to be quite efficient, provided some interaction is added and the incomplete data issue is dealt with. As will be shown, they helped us identify a number of clear patterns and exceptions in the data set.

\section{THE EXPERIMENT}

\subsection{Tax / surface proportionality: Charles de Fourcroy's tableaux poléométriques}

In 1782, Charles de Fourcroy - a French mathematician and scholar - designed what he called a tableau poléométrique (translated by [27] in "poleometric table") - nested geometric figures (squares, Figure 3) used to compare urban surfaces of major European cities (in his own words, "a kind of table that visually represents an idea of the actual proportion that can be found between the surfaces of these different cities" [27]).

His design, that M.Friendly [28] calls "an early tableau graphique", illustrates a key movement into abstraction [16]: the figure ceases to represent an object, a "real thing". But his design introduces other unsaid breakthroughs, and notably the concept of cluster: not only are cities "grouped" and "sub-grouped" by ranges of sizes ("very big", "big", etc.) but the values themselves are likely to have been approximated so as to create sort-of clusters (Milan, Naples and Madrid for instance are shown as cities of perfectly equal size).

The influence of Charles de Fourcroy's poleometric table is seemingly difficult to measure but his concept is, as will be shown, quite easy to reuse. One of the reasons for that is that he simply underestimated the capacity of the figure to convey additional information, beyond proportions of squares (in particular, colors are used only to differentiate a square from the next/previous one). Coming back to our data set, we did have an indication about the surfaces of wooden stalls (width and depth, in ells) - and naturally a first thing we did is draw a poleometric table for each commercial facility, where each stall is represented by a square.

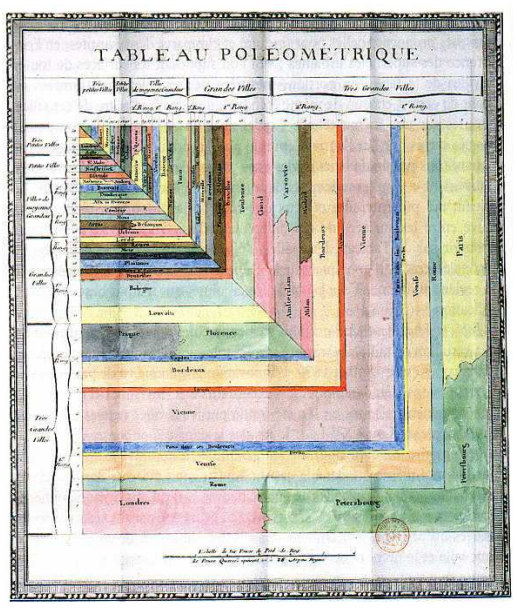

\section{Figure 3 : Charles de Fourcroy's Tableau Poléométrique [28].}

We also produced a poleometric table for the whole collection of commercial facilities, where each square represents the overall surface of all stalls in the facility. Once some interactivity is added, the result is a figure enhancing differences / similarities in surfaces inside one commercial facility, and across commercial facilities (Figure 4).

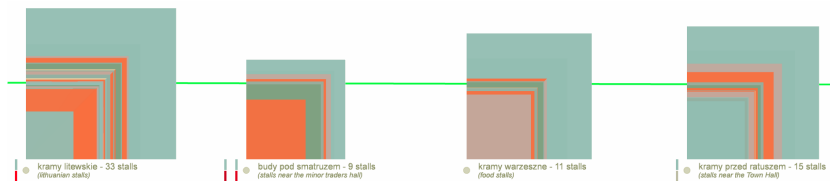

Figure 4 : Poleometric tables for $\mathbf{4}$ four groups of stalls

In the example above facilities of very different overall sizes are considered. On each of them it appears quite clearly that surfaces of stalls inside each facility widely differ - and in a way that could even be seen as totally chaotic. However, when looking from closer, a majority of surfaces are grouped, in all of those four facilities, around the green line's value (more or less 3 square meters, or 9 squares ells). Also noticeable, in each of the four edifices a stall stands out significantly as bigger in surface than the rest. Finally, the left tableau - corresponding to the Lithuanian stalls, shows a wider range of surfaces, which is quite understandable when knowing their overall number (33, far more than the others) and its approximate localisation, around the south-east corners of the market square (meaning most likely a facility composed of several, spatially independent, groups of stalls). Colour here still means nothing particular: it is only used to facilitate visual contrasts. But beyond surfaces our data set includes indications on tax levels before/after 1760 for each stall, and thereby on tax increases. This information is represented by a second poleometric table, that we somehow "mirrored" along the $\mathrm{X}$ axis (Figure 5), and inside which the colour now means either the tax level, or the tax increase (the brighter the red is red, the higher the value). Each stall is represented by a square in the top poleometric table (where the focus is put on surfaces and their variability), and by a corresponding square of same surface in the bottom poleometric table (where the focus is put on the variability of an additional parameter, here tax levels / increase, toggle on user demand). 

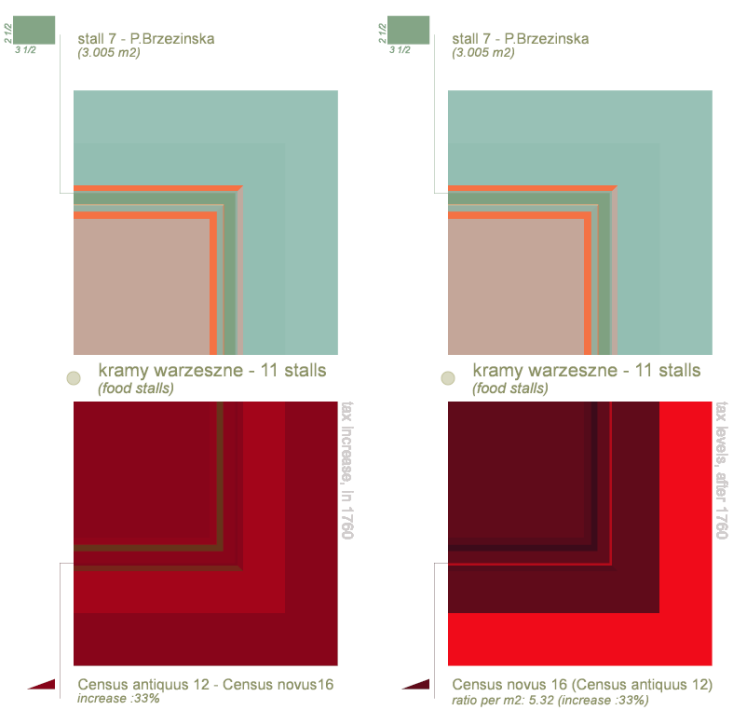

Figure 5: Bottom tables can show (left) tax increases or (right) tax levels for each stall in the top table.

As mentioned earlier, since we deal with historical data sets some information is missing: the issue is dealt by providing specific glyph or adapting the colour scheme (Figure 6).
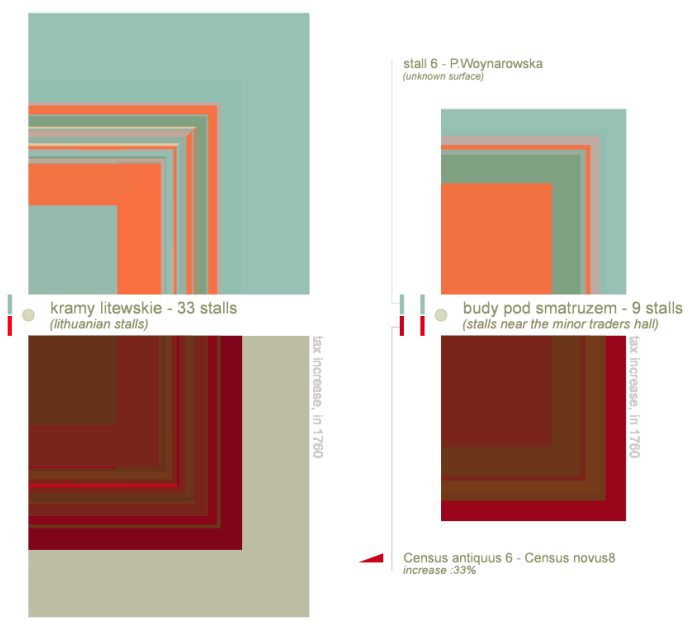

Figure 6: Handling missing information: left, unknown tax levels for the largest stall (represented by a grey surface). Right, unknown surface for two stalls (represented by two small rectangles and the tax info remains available).

Quite surprisingly if one considers the absolute simplicity of the visual formalism, some clear conclusions do emerge, in particular on tax / surface proportionality (Figure 7). Since the size of squares represents surfaces, if tax levels had been proportional to surfaces we would have bright red colours on the bigger squares, and progressively darker reds as the size of squares diminishes. Interpreting the visualisation becomes straightforward: bright and dark reds are NOT organised progressively, tax levels are NOT proportional to surfaces.

If that is so maybe the tax increase in 1760 was a sort of catchingup process? This possibility is also denied. Note that the fourth group of stalls' mostly highly taxed (Figure 7) is also the one for which the increase is the biggest (Figure 8). In short, there is apparently no simple relation of surface to tax levels or increase.

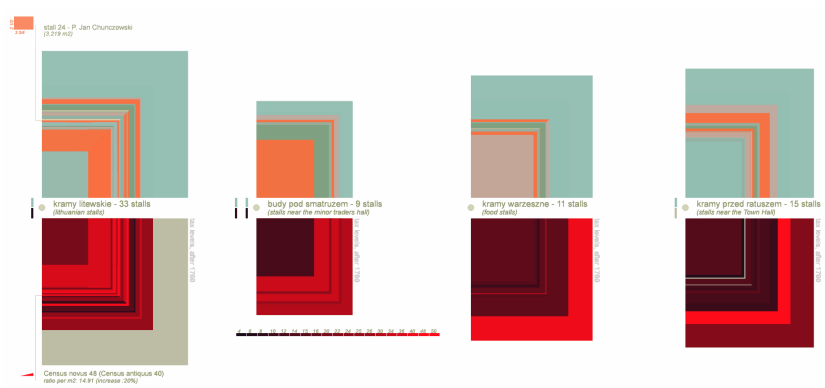

Figure 7: Surfaces and tax levels
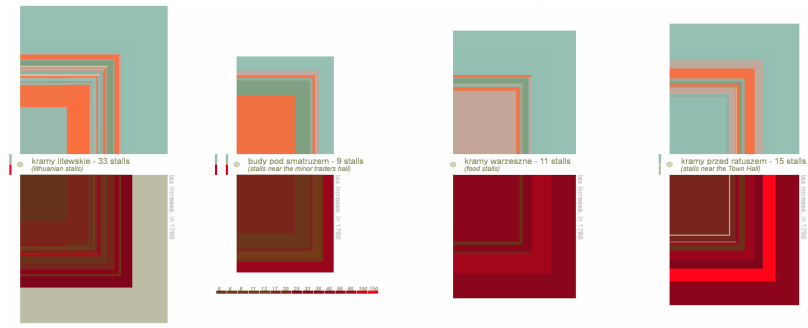

Figure 8: Surfaces and tax increases

The implementation includes various user interaction modalities (we do not mention here general functions like zoom/pan). "Mouseover" events are used to provide additional visual or textual information on each stall - order of appearance in the inventory, owner, approximative localisation, surface in square metres, width and depth in ells (represented by a rectangle), tax levels before and after 1760, increase rate given by value and represented as a slope (Figure 5). Values corresponding to the colour gradients are displayed on user demand (Figure 7, under the second group of stalls). Users may also decide on what to show in each table: surfaces, tax levels before and after 1760, tax increase (Figure 9).
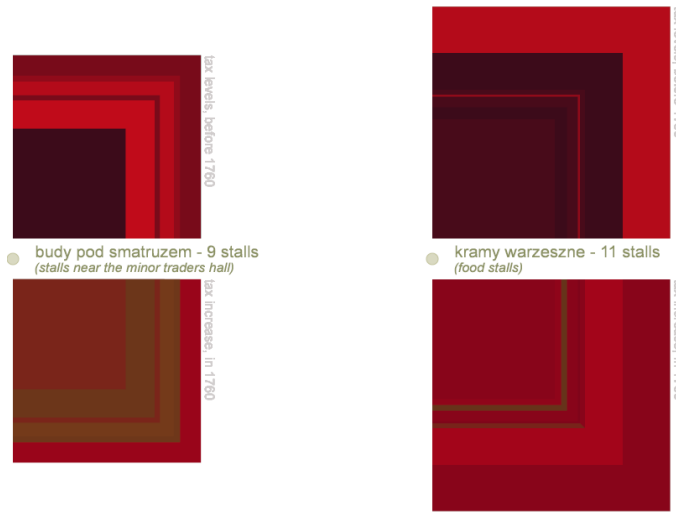

Figure 9: In this configuration the tables represent tax levels before (top row) and after (bottom row) the 1760 inventory, showing patterns of stability and change.

Finally, two other graphics can be displayed, on user demand, for a given group of stalls. The first is a sort-of histogram (Figure 10) showing on the right side stalls widths in descending order (top part) and stalls depths in descending order (bottom part). The scale of grey represents a proportionality indicator - the darker the grey, the more "dominant" the current dimension. A dark grey in the top part means width is significantly higher than depth.

Bars are then mirrored of the left side and tax levels represented with a gradient of red as in the poleometric tables (the brighter the 
red, the higher the tax level). The surface of the small squares aligned vertically in between the bars represents the tax ratio (tax per linear meter of width - top part - or depth - bottom part). The extreme diversity of tax ratios in the bottom part would suggest that if the tax was calculated basing not on a surface but on a length (linear meters of selling space), it was probably calculated on the width (if not, taxation policies had to be very unfair...).

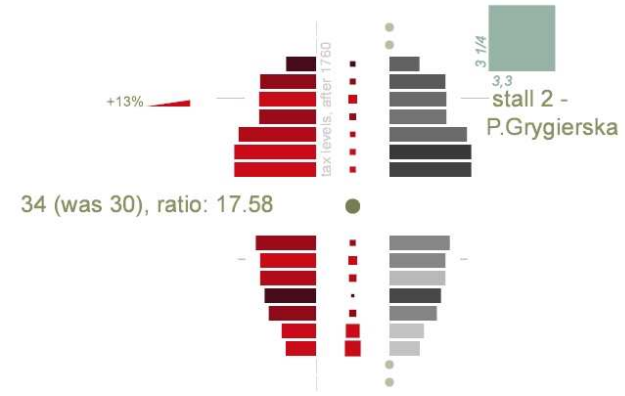

Figure 10: Top bars: stalls arranged by growing widths, bottom bars, stalls arranged by growing depths. Small squares in between represent tax ratios per linear meter of width (top part) or of depth (bottom part, far greater variability).

The second additional graphic can be seen as a 2D spatial puzzle, helping the analyst to test various spatial arrangements of stalls. It builds on the hypothesis that stalls sharing a common dimension (may it be width or depth) could have been aligned as a consistent row. Stalls are in aligned horizontally and vertically - the $x$ value is then the width, the y value the depth. A "mouseover" event allows users, on selection of a given stall, to check "which stalls in the group have the same width and the same depth". Then, once a given stall is selected, all stalls of comparable width OR depth are aligned, and the remaining stalls presented as a group (Figure $11)$.

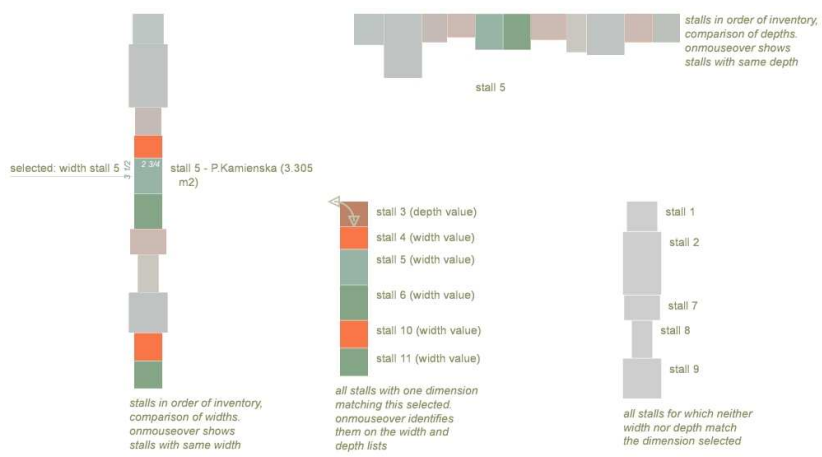

Figure 12: On user demand a combination of stalls that match a regular alignment constraint is drawn, and the remaining stalls are represented as greyish rectangles. Used as support for workgroup discussions, the visualisation helped weigh the odds of a classic, regularly aligned spatial organisation.

These additional graphics are designed to help analysts think aloud in workgroups, and, as such, complement the poleometric tables in later stages of the analysis process.

\subsection{Tax /position interrelations: Munehisa Homma's candlestick charts}

Candlestick charts originate from Japan where in the early XVIIIth a rice trader called Munehisa Homma used them to represent visually the movement over time of rice prices (debate over the actual origin of candlesticks can be found in [29]). Traditional candlestick charts (Figure 12) represent the changes of value for a "good" during a time interval, and summarize four indications:

price of the good at the open and the close, represented as a box called the body (filled black when prices fall, white when they raise)

- maximum and minimum prices during the interval, called upper and a lower shadow (wick).

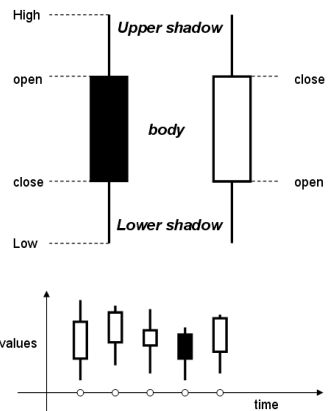

Figure 12: The "classic" candlestick

When wanting to observe changes over time on a longer period, candlesticks are presented along the $\mathrm{X}$ axis as a time series (Figure 13). Unlike poleometric tables, candlestick charts are known and used worldwide: they remain today a popular visual tool in the world of trading and financial analysis. The concept, however, can be adapted to other fields of concern - the wikipedia page on candlestick charts for instance illustrates an application to meteorological data. The concept could in fact be adapted to any situation where a limited number of quantitative variables need to be observed in ordinal time. But our re-vision of candlesticks introduces a quite significant shift. Each candlestick represents, for a given stall, the following information (Figure 14):

- tax levels before and after 1760 (height of the body, when levels are unchanged a specific glyph is displayed),

- tax increase (colour of the body),

- ratio per square meters before and after 1760 (upper and a lower shadows),

- average and maximum values for that ratio across the group of stalls (small horizontal grey lines above and below the body).

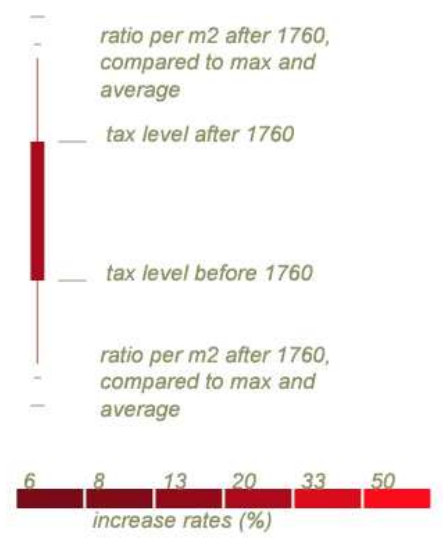

Figure 13: The information encoded in a candlestick

When information on tax levels is missing, we have the stall represented by a grey dot on the $\mathrm{X}$ axis, and when information on surfaces is missing the shadows of the candlestick are replaced by 
a small grey square. Candlesticks for each stall inside a facility are then represented side by side, in the inventory's order of appearance. In other words, what we show is not a time series any more but a "spatial" series - with each candlestick corresponding to a stall, to a location (an order) in space.

Interactivity is here quite basic - on user demand values for tax levels can be displayed, along with the legend and its colour scale (the colour scale is recalculated for each group of stalls so as to enhance differences, but can be blocked to fixed values when comparing several groups). A rectangle representing the surface and shape of the stall can also be displayed on user demand, along with the stall's owner name. Noticeably, this "re-vision" of the original candlestick concept does shed a clearly new light on our data set, highlighting striking patterns inside each facility, or across facilities, as shown in the two examples below (Figures 14, $15)$.

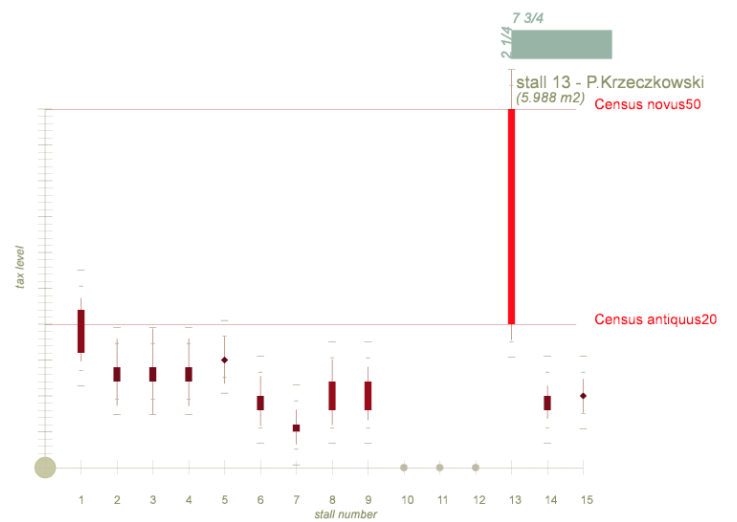

Fig 14: Candlesticks for the "Stalls near the Town Hall": stall 13 clearly appears as an Outlier. Wrong data? Specific position? When observing the shape of the stall, its width also strikes out, suggesting this specific stall might have been a lasting wooden structure resting against a wall of the Town Hall itself when the rest of the stalls were mobile structures installed in the same area.

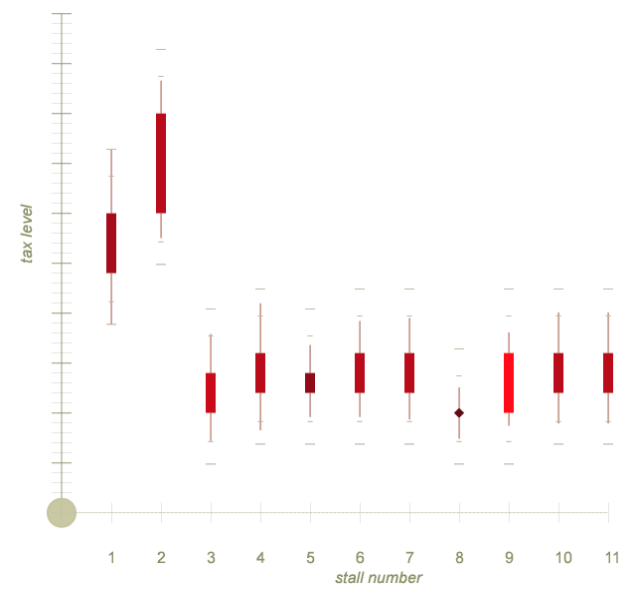

Fig 15: Candlesticks for the food Stalls. The two first stalls significantly stand out, which can be connected to specific goods, but could also suggest a possible prominence in terms of spatial layout (maybe something like today's "aisle head" position used to promote products in supermarkets). Also note that in most cases the tax ratio before and after 1760 remains the same (lower and upper shadows).
Both the poleometric tables and the candlestick charts have proven efficient in workgroup discussions, where they allow a fast and clear-cut invalidation of biases, easy judgments, popular misconceptions and generally accepted ideas. It should be said though that these graphics help us to spot questions, rather than to give answers (the latter being often out of direct reach in Historical Sciences). Those questions then act as potential evidence, needing cross-examination, and nothing more.

\section{EVALUATION AND FUTURE WORK}

Evaluation is here somehow arduous: proving the visual formalisms can be helpful and efficient is something like a mere pleonasm once we have shown how they impacted our understanding of the data set. Besides, the context of the research - a specific question, addressed by a small group of "experts" was such that issues like the quality of the interfacing and of the interactivity were probably not key to test (what we did check though, but informally, is the capacity of such simple visual design to foster discussions in workgroups). We could of course also have compared the performances of other suitable but more recent solutions like mosaic plots or treemaps (although newcomers in visual reasoning - historians for instance, at ease with Latin texts but not with abstract graphics - may not feel familiar with such formalisms). Instead, what we did is consider the evaluation issue from another point of view - this of the capacity of our two classic visual formalisms to be considered as efficient generic solutions. We therefore developed an Internet implementation allowing users to post a data set (CSV format) and retrieve an SVG poleometric table. The data set must include for each item three parameters:

- a label (qualitative),

- a surface parameter (any quantitative parameter, may it correspond or not to a physical surface),

- a density parameter (quantitative) represented in the bottom table (the more red, the more dense).

The idea is to try and learn from users, in this sort-of crowdsourcing approach, whether the simplicity of the concept, and whether the actual implementation we propose, can really be adapted to a variety of situations. A preliminary feasibility test was conducted within our research unit. Several data sets were tested: city sizes vs. population; computer disk use vs. number of files, size of forces engaged in a battlefield vs. duration of the battles or vs. losses (Figures 16), size of book vs. number of pages for various editions, farmland use vs. size of farms, etc.

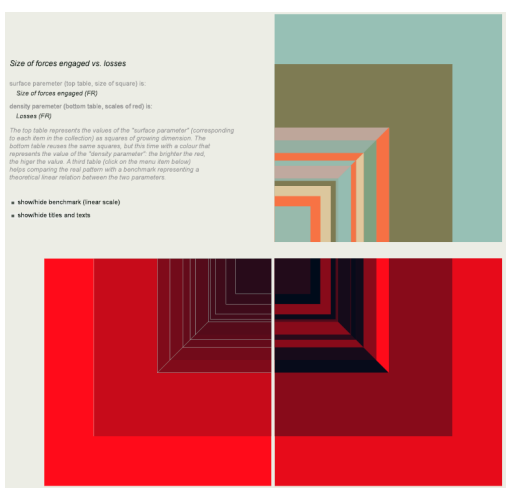

Figure 16: A generic application to size of forces engaged in a battlefield vs. losses (data extracted from Wikipedia). The bottom left table shows the linear benchmark - (linear proportionality of forces engaged to losses). 
These tests already allowed us to harvest a certain number of feedbacks (minuses, open questions or expected improvements), notably:

- readability and scale of values: a good readability requires a range of surfaces (first parameter) between 1 and 20, thereby limiting the use of poleometric tables to such situations;

- clustering: the current implementation creates automatic kind-of clusters by approximating decimal values. A critical improvement would be to allow user-monitored clustering so as to avoid visual discomfort when surfaces are "almost" overlapping;

- comparison enhancement : a proposition was made to display the density parameter "as expected if it was in a linear scale relation with the surface parameter" (or any other relation), so as to gauge the differences between a benchmark and the real pattern (Figure 16);

- user configuration and interaction : the actual colour gradient is system-defined, an improvement would be to allow user-choices for the colour and the orientation of the gradient;

This approach is primarily intended at having the needs of users resurface, and the range of potential reuses of the formalisms assessed. But what we more generally expect from this experiment, with time, and expectably a number of faulty attempts, is to get a better understating of the actual benefits of Charles de Fourcroy's solution: a nice old thing, or something worth re-examining?

\section{CONCLUSION}

In this contribution we introduced a reuse of "great classics" in a new context: the need to uncover patterns and exceptions inside a data set consisting of incomplete historical evidence on groups of stalls that used to be located on the market square in Cracow.

The experiment shows that once reinterpreted and reimplemented, equipped with ad-hoc interactivity, classic visualisations like Charles De Fourcroy's tableaux poléométriques or Munehisa Homma's candlestick charts do help the analyst to re-read the data, to augment his level of knowledge, and ultimately can boost workgroup discussions. It should be said clearly though that our objective was not to prove that poleometric tables and candlestick charts are unavoidable research tools when facing incomplete historical data sets. In particular, we make no claim other visual solutions could have helped us reach exactly the same conclusions concerning the tax/surface interrelations or the tax /position interrelations. What we did is show that, although they are very simple concepts, and not related to our field of application, they can be fruitfully revisited. We then proposed a generic implementation aimed at weighing to which extent what was true for us could be true elsewhere.

By this, we believe this contribution underlines a more general issue: testing out a sort of "reverse workflow". In other words, instead of observing a data set, then formulating questions, and finally deriving from these questions some visual tool, why not try and do precisely the contrary:

observe and understand a classic visualization,

think out how it could be applied in the context of a data set,

ultimately, verbalize a question that had not even come to the mind, or introduce new metrics for the data set under scrutiny.

J.Bertin wrote that "Graphics [...] an answer to a question" [30], and we acknowledge he was perfectly right. But what if we tested it the other way round: "Graphics: a potential question yet unthought-of?" Naturally it has to be said strongly that in no way do we consider this "reverse workflow" as a potential central part of the analysis process. But this research shows that it is worth trying it out. This is what we did in yet another experiment, this time revisiting C.J Minard's tableaux graphiques (in a rather loose way, however)

The original solution was meant to analyse commercial traffic along a canal in Burgundy (France). The $\mathrm{X}$ axis corresponded to distances from a fluvial port to another and the $\mathrm{Y}$ axis corresponded to the quantity of goods transported. Accordingly the surface of rectangles represented the price of the delivery [16].

In our interpretation, applied to major edifices of the market square in Cracow, the $\mathrm{X}$ axis corresponds to each edifice's surface (a quantity, in square meters) and the $\mathrm{Y}$ axis to its lifeline (a quantity, in years). The surface then represents an unthought-of metrics dedicated at historic architecture: a "sustainable usability" measure (Figure 17). The idea is simple: an edifice can be considered as more "useful" if it is big, but also if it lasts long. In our interpretation, of C.J Minard's "tableaux graphiques", the surface of a rectangle corresponds to that idea: the bigger the edifice the bigger the rectangle, and the more long-lasting the edifice the bigger the rectangle.

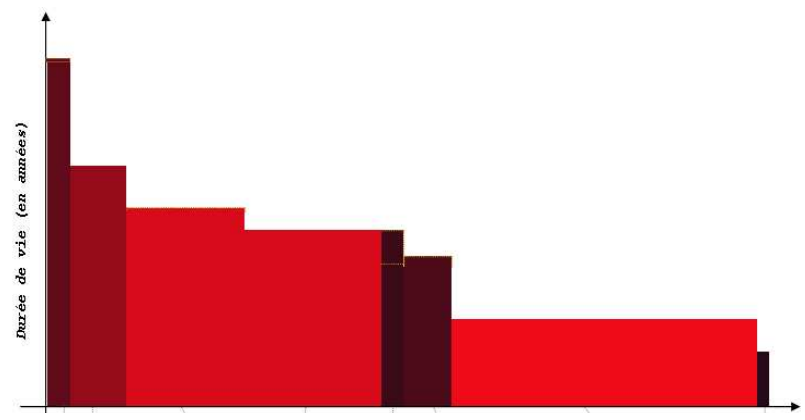

Figure 17: A "sustainable usability" measure (the bigger the rectangle, the more bright red its filling colour). Proportionality of surfaces (represented by the red colour scale) remains the same whatever unit is used on the axes.

To conclude, one of this paper's claims is that the power of many hand-drawn masterpieces probably lies somewhere in the following aspects:

- a simplicity of design, something like a "less is more" rule,

- a high readability for non-experts,

- a potential of reuse, in close relation with simplicity of design.

Besides, this contribution underlines some other expected benefits of simplicity (simplicity fosters a fast, clear-cut, and sharable invalidation of biases and easy judgments, and facilitates workgroup discussions with people rooted in Human Sciences, not familiar with abstract graphics or highly interactive environments).

But it also underlines another benefit, and a key one when rereading data sets: simplicity compels the analysts to a dramatic dimensionality reduction and, as a consequence, uncovers lines of thought, open issues, unthought-of metrics. In that sense, revisiting simple classics did not only remind us that simplicity, in the sense of Maeda, can help - reducing, organizing, "subtracting the obvious, and adding the meaningful" (three of Maeda's laws of simplicity) are rather consensual aims. Revisiting classics acted as food for rethinking a data set, and re-questioning it. 


\section{REFERENCES}

[1] Aigner, W., Miksch, S., Schumann, H., Tominski, C. 2011. Visualization of Time-Oriented Data Springer: Human-Computer Interaction Series.

[2] Keim, D., Kohlhammer, J., Ellis, G., Mansmann, F., 2011. Mastering the Information Age - Solving Problems with Visual Analytics. Konstanz : University of Konstanz. http://www.vismaster.eu/

[3] Spence, R., 2006. Information Visualization: Design for Interaction. Prentice-Hall.

[4] Geroimenko, V., Chen, C. (Eds), 2010 Visualizing Information Using $S V G$ and X3D, Springer-Verlag, ISBN 1-84996-918-3.

[5] Card, S.K., Mackinlay, J.D and Schneiderman, B. 1999 Information vizualisation: Using vision to think. Morgan-Kaufmann, San Francisco, CA, USA.

[6] Andrienko N., Andrienko G. 2009 Interactive Cluster Analysis of Diverse Types of Spatiotemporal Data In SIGKDD Explorations Volume 11, Issue 2 ACM New York, NY, USA, DOI= dl.acm.org/citation.cfm?doid=1809400.1809405

[7] Seifert, C., Sabol, V., Kienreich, W., Lex, E., and Granitzer, M. 2014 Visual Analysis and Knowledge Discovery for Text. In Large-Scale Data Analytics Gkoulalas-Divanis, Aris, Labbi, Abderrahim (Eds.) Springer New York, 189-218. DOI= link.springer.com/chapter/10.1007/978-1-4614-9242-9_7

[8] Krstajic M, Rohrdantz C, Hund M, Weiler A. 2012 Getting There First: Real-Time Detection of Real-World Incidents on Twitter In Proceedings of the 2nd IEEE Workshop on Interactive Visual Text Analytics -IEEE VisWeek 2012 (Seattle, WA, USA, October 15th, 2012)

[9] Gschwandtner, T., Gärtner, J., Aigner, W., and Miksch, S., 2012. A Taxonomy of Dirty Time-Oriented Data, In Proceedings of the CD-ARES 2012 (Prague, Czech Republic, Aug 20- 24, 2012) Lecture Notes in Computer Science (LNCS 7465) Springer, Berlin / Heidelberg, 58 72. DOI= link.springer.com/chapter/10.1007\%2F978-3642-32498-7_5

[10] Boyandin I, Bertini E, Lalanne D. 2012 A Qualitative Study on the Exploration of Temporal Changes in Flow Maps with Animation and Small-Multiples. In Computer Graphics Forum, International Journal of the Eurographics Association, Eurographics/IEEE-VGTC Symposium on Visualization (Vienna, Austria, June 2012). Wiley, DOI= 10.1111/j.1467-8659.2012.03093.x

[11] Tufte, E.R., 2001 (or. ed. 1983) The Visual Display of Quantitative Information. Graphics Press, Cheshire, CT, USA.

[12] Tufte, E.R., 1990 Envisioning Information. Graphics Press, Cheshire, CT, USA.

[13] Tufte, E.R., 1997 Visual Explanations: Images and Quantities, Evidence and Narrative. Graphics Press, Cheshire, CT, USA.

[14] Tufte, E.R., 2006 Beautiful Evidence. Graphics Press, Cheshire, CT, USA.
[15] Friendly, M 2008. A brief history of data visualization. In handbook of computational statistics: data visualization. C.Chen W.Hardle A.Unwin (Eds.) Springer-Verlag, Heidelberg, 15-56. DOI=http://link.springer.com/book/10.1007\%2F978-3540-33037-0

[16] Palsky, G. 1996 Des chiffres et des cartes - La cartographie quantitative au XIXème siècle CTHS.

[17] Rosenberg D., Grafton A. 2010. Cartographies of Time Princeton Architectural Press, New York, NY, USA.

[18] Friendly, M. 1999. Revisions of Minard Statistical Computing and Graphics Newsletter, Vol. 11, No. 1

[19] Friendly, M. 2002. Visions and Re-visions of Charles Joseph Minard, Journal of Educational and Behavioral Statistics, 2002, Vol. 27, No. 1, 31-51. DOI $=10.3102 / 10769986027001031$

[20] Kraak, M.J. 2003 Geovisualization illustrated In ISPRS Journal of Photogrammetry \& Remote Sensing 57 390399. DOI $=10.1016 / \mathrm{S} 0924-2716(02) 00167-3$

[21] Maeda, J. 2006 The Laws of Simplicity MIT Press, Cambridge, MA, USA.

[22] Schuller, G. 2009 Designing universal knowledge. Lars Müller Publishers, Baden, $\mathrm{CH}$.

[23] Dudek,I, Blaise, J.Y 2008. Visual assessment of heritage architecture life cycles. In Proceedings of the 8th International Conference on Knowledge Management IKnow 2008, I-Know I-Media 08, (Graz, Austria, Sept 2008) JUCS, ISSN 0948-695x.

[24] [Dudek 07] Dudek I., et al: "Visual tools decipher historic artefacts documentation", Proc. I-KNOW 07, Graz, JUCS, (2007)

[25] Blaise, J.Y., and Dudek, I., 2011 Concentric Time: Enabling Context+Focus Visual Analysis of Architectural changes In Foundations of Intelligent Systems, edited by M. Kryszkiewicz, H. Rybinski, A. Skowron, W. Raś, 632-641, Lecture Notes in Computer Science, Berlin, Heidelberg : Springer-Verlag.

[26] Dudek, I., and Blaise, J.Y. 2011 "Visualizing alternative scenarios of evolution in heritage architecture" In Proc. of the 11th International Conference on Knowledge Management and Knowledge Technologies, ICPS: edited by S. Lindstaedt and M. Granitzer, 45-52. ACM International Conf. Proceeding Series New York :ACM.

[27] Des cartes générales aux cartes spéciales, translation of [16], pp50-51, by Daniel J. Denis 2002 http://euclid.psych.yorku.ca/SCS/Gallery/milestone/fourc roy.html

[28] Friendly, M, and Denis, D.J. Milestones project, http://www.datavis.ca/milestones/index.php?group $=1700$ $\mathrm{s} \& \mathrm{mid}=\mathrm{ms} 78$

[29] Fogle, B. The Art of Japanese Candlestick Charting http://www.optionsuniversity.com/CandlestickSecrets/Bo ok/candlesticksecrets.pdf

[30] Bertin, J., 1983 Semiology of Graphics: Diagrams, Networks, Maps. The University of Wisconsin Press, ISBN 0299090604 (out of print). 